\title{
Identifikasi Varietas Benih Jagung (Zea Mays L.) Menggunakan Pengolahan Citra Digital Berbasis Jaringan Syaraf Tiruan
}

\author{
Mohamad Ihya Ulum Muddin \\ Program Studi Teknik Pertanian \\ Universitas Jember \\ mohihya.ulum@gmail.com
}

\author{
Dedy Wirawan Soedibyo \\ Program Studi Teknik Pertanian \\ Universitas Jember \\ dedy.soedibyo@gmail.com
}

\author{
Sri Wahyuningsih \\ Program Studi Teknik Pertanian \\ Universitas Jember \\ sriwahyuningsih.ftp@unej.ac.id
}

\begin{abstract}
Abstrak - Identifikasi varietas perlu dilakukan untuk membedakan galur yang dihasilkan dengan varietas yang telah ada sehingga sangat penting bila dikaitkan dengan perlindungan varietas tanaman dan hak kekayaan intelektual. Salah satu metode yang umum diterapkan untuk identifikasi varietas jagung adalah dengan cara mendeskripsikan morfologi benih. Namun, hal tersebut membutuhkan waktu lama dan sulit jika dilakukan pengukuran secara manual. Pengolahan citra (image processing) dan jaringan syaraf tiruan (JST) dapat dijadikan sebagai salah satu metode identifikasi varietas yang dapat membantu mengidentifikasi varietas benih jagung. Penelitian ini bertujuan untuk mengetahui variabel citra yang dapat digunakan untuk identifikasi varietas benih jagung sehingga dapat disusun algoritma jaringan syaraf tiruan terbaik dan mengetahui tingkat akurasinya dalam menduga varietas benih jagung. Sampel yang digunakan dalam penelitian ini adalah benih jagung hibrida BISI 18, Pioneer P21, Pioneer P27 dan PERTIWI. Pada masing-masing varietas diambil 600 sampel untuk data training dan 200 sampel untuk data testing, keseluruhan sampel adalah 3200 benih jagung. Penelitian ini menggunakan pengolahan citra digital dengan menggunakan analisis statistik untuk menentukan variabel yang dapat dipergunakan dalam penerapan jaringan syaraf tiruan sebagai metode identifikasi. Hasil penelitian menunjukkan variasi JST terbaik untuk menyusun program identifikasi benih jagung adalah variasi A3 dengan 20 node hidden layer. Hasil validasi menunjukkan, program identifikasi benih jagung memiliki tingkat akurasi dalam menduga varietas sebesar 59,1\%.
\end{abstract}

Kata Kunci: Backpropagation, Benih Jagung, Citra Digital, Identifikasi Varietas, Jaringan Syaraf Tiruan.

\section{PENDAHULUAN}

Identifikasi varietas menjadi sangat penting bila dikaitkan dengan perlindungan varietas tanaman dan hak kekayaan intelektual. Identifikasi varietas benih jagung diperlukan untuk membedakan galur yang dihasilkan dengan varietas yang telah ada. Salah satu metode yang umum diterapkan untuk identifikasi varietas jagung adalah dengan cara mendeskripsikan morfologi benih. Morfologi mempunyai ciri yang penting dalam penentuan varietas seperti ukuran, warna, area dan bentuk benih. Beberapa ciri tersebut membutuhkan waktu lama dan sulit jika dilakukan pengukuran secara manual dan harus dilakukan oleh tenaga ahli. Cara yang tepat untuk mendeskripsikan ciri tersebut yaitu dengan menggunakan pengolahan citra digital. Pengolahan citra merupakan bidang tersendiri yang mampu menangani data teks dan data citra berdasarkan sistem visual yang memiliki tingkat akurasi jauh lebih tinggi dari visual manusia [1]. Proses identifikasi varietas benih jagung dengan pengolahan citra digital, akhirnya dapat dilakukan tanpa memerlukan tenaga ahli.

Berdasarkan uraian di atas maka diperlukan suatu metode yang mampu melakukan identifikasi varietas benih jagung yaitu dengan menggunakan pengenalan pola. Pola-pola tersebut dikenali melalui teknik pengolahan citra digital dan jaringan syaraf tiruan. Pengolahan citra menggunakan sistem visual berdasarkan sensor elektro-optika mempunyai kemampuan yang lebih peka, tepat, dan objektif daripada kemampuan visual manusia [2]. Pengolahan citra mampu menyediakan sifat-sifat citra secara kuantitatif (variabel citra) yang dibutuhkan sebagai input pengenalan pola. Untuk meningkatkan keakuratan dalam identifikasi benih jagung perlu adanya metode pendukung yaitu jarigan syaraf tiruan (JST). JST adalah sebuah konsep yang meniru cara kerja jaringan syaraf pada otak manusia dan dapat dilatih untuk mempelajari sesuatu. Keuntungan dari metode JST adalah dapat membangun fungsi non linier dan hanya memerlukan data masukan dan keluaran tanpa mengetahui dengan jelas proses dalam jaringan [3]. Hal ini cocok diterapkan pada data citra.

Beberapa variabel citra yang digunakan dalam teknik pengolahan citra digital dan jaringan syaraf tiruan yaitu warna, area, tinggi, lebar, perimeter dan faktor bentuk. Fitur citra tersebut mungkin dapat digunakan sebagai variabel untuk identifikasi varietas benih jagung, sehingga dengan menggunakan variabel yang lebih banyak diharapkan dapat mengenali varietas benih jagung dengan akurat. 


\section{METODOLOGI PENELITIAN}

\section{A. Pengenalan Pola (Pattern Recognition)}

Pengenalan pola merupakan proses atau pekerjaan untuk mengklasifikasikan kelompok atau kategori pola berdasarkan ciri-ciri yang dimiliki pola tersebut. Bentuk suatu objek tertentu dalam dunia nyata dapat dibandingkan dengan pola pola dasar dalam citra, sehingga penggolongan objek dapat dilakukan dengan mudah [1]. Dalam pengenalan pola ada 2 pendekatan yang dilakukan yaitu pendekatan secara statistik dan pendekatan secara sintatik atau struktural. Dalam penelitian ini pendekatan yang dilakukan yaitu pengenalan pola secara sintatik atau menggunakan data-data statistik.

\section{B. Pengolahan Citra (Image Processing)}

Pengolahan citra adalah proses untuk mengamati dan menganalisis suatu objek tanpa berhubungan langsung dengan objek yang diamati. Perangkat keras dalam pengolahan citra yakni kamera dan alat peraga. Sensor citra yang umum digunakan yaitu kamera CCD. Perangkat lunak yang digunakan dalam melakukan pengolahan citra digital ada 2 yaitu jenis yang bisa diprogram (programmable) dan tidak bisa diprogram (non-programmable) [1]. Pengolahan citra yang dilakukan pada penelitian ini menggunakan perangkat lunak programable yang dibangun menggunakan program Sharp Develop 4.4.

\section{Ekstraksi Citra}

Ekstraksi citra yaitu proses mendapatkan nilai variabel mutu citra dengan melakukan operasi tertentu pada pikselpiksel pembentuk citra [4]. Variabel mutu yang diambil dari proses ekstraksi citra diantaranya yaitu area, ukuran, perimeter dan pengolahan warna.

\section{Jaringan Syaraf Tiruan}

Jaringan syaraf tiruan adalah sistem pemroses informasi yang memiliki karakteristik mirip dengan jaringan syaraf biologi. Jaringan syaraf tiruan ditentukan oleh 3 hal yaitu pola hubungan antar neuron atau disebut juga arsitektur jaringan, metode untuk menentukan bobot penghubung dan fungsi aktivasi. Jaringan syaraf tiruan merupakan generalisasi model matematika dari jaringan syaraf biologi. Jaringan syaraf tiruan merupakan generalisasi model matematika dari jaringan syaraf biologi [5].

\section{E. Backpropagation}

Backpropagation merupakan algoritma pembelajaran yang terawasi dan biasanya digunakan oleh jaringan dengan banyak lapisan untuk mengubah bobot-bobot yang terhubung dengan neuron-neuron yang ada pada lapisan tersembunyinya [6]. Pelatihan backpropagation meliputi 3 fase yaitu fase maju, fase mundur dan fase modifikasi/perubahan bobot [5].

\section{F. Alat}

Alat yang digunakan antara lain kamera $\mathrm{CCD}$, kain tetron putih, 4 lampu TL 15 Watt, meja pengambilan gambar, perangkat komputer, software IC Capture 2.2, software Sharp Develop 4.4, software Ms. Excel 2016, software Matlab 2015a, dan software Jasc Paint Shop Pro.

\section{G. Bahan}

Bahan yang digunakan dalam penelitian ini adalah benih jagung hibrida PERTIWI 3, BISI 18, Pioneer P21 dan Pioneer P27. Pada masing-masing benih diambil 600 sampel untuk data training dan 200 sampel untuk data testing, sehingga keseluruhan sampel adalah 3200 benih jagung.

\section{H. Prosedur Penelitian}

Prosedur penelitian identifikasi varietas benih jagung (Zea Mays L.) menggunakan pengolahan citra digital berbasis jaringan syaraf tiruan dijelaskan sebagai berikut.

a) Sortasi Awal

Sortasi awal dilakukan guna menjamin keseragaman terhadap varietas yang sudah ditentukan. Sortasi sampel yang dilakukan yaitu berdasarkan varietas jagung hibrida Pertiwi 3, BISI 18, Pioneer P21 dan Pioneer P27.

b) Image Aqusition

Proses ini dilakukan dengan penentuan jarak kamera dan penentuan proses penyinaran hingga didapatkan hasil citra belimbing yang mendekati aslinya, sedikit timbul bayangan, dan tidak ada cahaya berlebih yang mempengaruhi warna objek. Metode penentuan image aquisition adalah trial and error.

c) Pengambilan Citra

Pengambilan citra sampel dilakukan menggunakan perangkat meja pengambilan gambar dan kamera CCD. Pengambilan citra dilakukan dengan cara merekam citra dalam bentuk format RGB beresolusi 1024 x 768 piksel dengan ekstensi .bmp dalam penyimpanan hard drive.

d) Pendugaan Variabel Citra

Pendugaan variabel citra dalam identifikasi varietas jagung adalah prediksi hubungan antara variabel fisik benih jagung dengan variabel citra. Penjelasan tentang dugaan hubungan antara kriteria varietas jagung dan variabel citra dijelaskan pada Tabel 1.

Tabel 1. Pendugaan Variabel Fisik Benih Jagung dan Variabel Citra

\begin{tabular}{ll}
\multicolumn{1}{c}{ Variabel Fisik } & \multicolumn{1}{c}{ Variabel Citra } \\
\hline Ukuran & Lebar dan tinggi \\
Berat (gram/1000 butir) & Area \\
Warna & r, g, dan b \\
Bentuk & Faktor bentuk \\
\hline
\end{tabular}

e) Pembuatan Program Pengolahan Citra

Program pengolahan citra dibuat dengan menggunakan perangkat lunak SharpDevelop 4.4 dengan bahasa pemrograman C\#. Program ini dibuat untuk melakukan ekstraksi variabel citra berupa indeks warna, area, lebar, tinggi dan perimeter. Hasil dari ekstraksi citra dari program ini disajikan dalam bentuk file teks (.txt).

f) Ekstraksi Variabel Citra

Ekstraksi citra dilakukan untuk mengukur indeks warna objek, area, lebar, tinggi, dan perimeter. Ekstraksi citra dilakukan menggunakan program pengolahan citra yang 
dibuat terlebih dahulu menggunakan program Sharp Develop 4.4.

g) Analisis Data

Hasil ekstraksi citra indeks warna, area, lebar, tinggi, dan perimeter perlu dianalisis dengan ukuran statistik untuk mengetahui korelasi antara variabel fisik dengan variabel citra. Statistik yang digunakan adalah rerata, standar deviasi, Q1 (kuartil pertama), Q2/median (kuartil kedua), Q3 (kuartil ketiga), nilai minimum, dan maksimum. Selanjutnya nilai-nilai variabel mutu yang telah ditabulasi digambarkan dalam grafik boxplot.

h) Training Jaringan Syaraf Tiruan

Masing-masing data memiliki variabel citra berupa indeks warna, area, lebar tinggi, dan perimeter. Variabel citra yang memiliki korelasi dengan variabel fisik varietas jagung akan digunakan sebagai input jaringan syaraf tiruan. Proses training jaringan syaraf tiruan menggunakan arsitektur backpropagation yang diolah menggunakan program MATLAB R2015a. Data yang digunakan sebagai training jaringan syaraf tiruan yaitu 600 sampel data pada tiap varietas, dengan jumlah varietas yang diteliti sebanyak 4 varietas sehingga total sebanyak 2400 data.

i) Pengujian dengan Propagasi Maju dan Pemilihan Arsitektur Terbaik

Propagasi maju dilakukan dengan menggunakan data testing sebagai input yang dinormalisasikan. Nilai bobot yang telah dikoleksi pada proses training jaringan syaraf tiruan digunakan sebagai formula propagasi maju. Pasangan bilangan yang diperoleh (output) digunakan untuk mengidentifikasi varietas benih jagung.

j) Pembuatan Program Identifikasi Benih Jagung

Program identifikasi varietas benih jagung dibuat untuk melakukan analisis nilai variabel citra untuk menentukan varietas benih jagung. Nilai-nilai bobot hasil pelatihan jaringan syaraf tiruan terbaik diintegrasikan dalam program pengolahan citra sehingga secara otomatis program dapat mengidentifikasi varietas benih jagung. Hasil analisis dari program ini disajikan dalam bentuk teks (.txt).

k) Validasi Program

Proses validasi program dilakukan untuk menguji akurasi program penentuan varietas jagung. Proses validasi dilakukan dengan menggunakan program penentuan varietas benih jagung. Data yang digunakan sebagai training jaringan syaraf tiruan yaitu 200 sampel data pada tiap varietas, dengan jumlah varietas yang diteliti sebanyak 4 varietas sehingga total sebanyak 800 data.

\section{HASIL DAN PEMBAHASAN}

\section{A. Pengolahan Citra Benih Jagung}

Citra benih jagung diambil dengan menggunakan kamera CCD (Charge Coupled Device) dengan hasil citra format .bmp (bitmap) 24 bit yang beresolusi 1024 x 768 piksel. Sejumlah 3200 citra benih jagung diproses menggunakan program pengolahan citra yang dibangun menggunakan program SharpDevelop 4.4 dengan bahasa pemrograman C\#. Dalam satu file citra terdapat 20 benih jagung yang ditata dengan formasi $5 \times 4$ berbentuk persegi. Penataan dilakukan agar program pengolahan citra bisa menganalisis karakteristik fisik masing-masing benih jagung dengan hasil berupa nilai-nilai variabel citra dalam satu kali proses. Variabel citra yang digunakan sebagai acuan untuk dihitung dalam proses identifikasi benih jagung yaitu area, perimeter, lebar, tinggi dan indeks warna RGB. Tampilan program pengolahan citra yang dibangun ditampilkan pada Gambar 1 beserta fungsi pada masing-masing komponen kerja program pada Tabel 2 sebagai berikut.

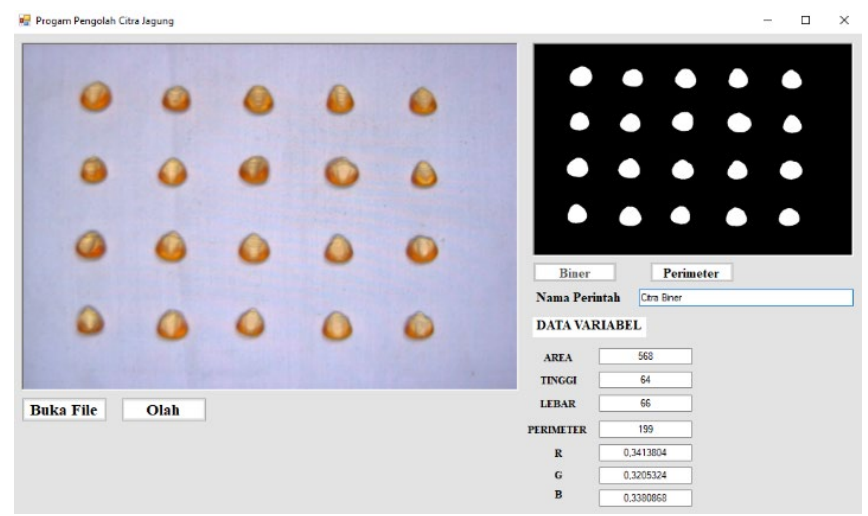

Gambar 1. Tampilan Program Pengolahan Citra Benih Jagung

Tabel 2. Komponen Kerja Program Pengolahan Citra Benih Jagung

\begin{tabular}{|c|c|c|}
\hline No & Komponen & Fungsi \\
\hline 1 & origImage & $\begin{array}{l}\text { Menampilkan citra asli benih jagung } \\
\text { sebagai objek }\end{array}$ \\
\hline 2 & procImage & $\begin{array}{l}\text { Menampilkan citra benih jagung } \\
\text { dalam format biner atau perimeter }\end{array}$ \\
\hline 3 & Buka File & $\begin{array}{l}\text { Membuka direktori pada komputer } \\
\text { untuk mencari file citra dan akan } \\
\text { ditampilkan pada picturebox } \\
\text { "origImage" }\end{array}$ \\
\hline 4 & Olah & $\begin{array}{l}\text { Perintah untuk mengolah file citra } \\
\text { yang dibuka }\end{array}$ \\
\hline 5 & Biner & $\begin{array}{l}\text { Perintah untuk menampilkan citra } \\
\text { benih jagung dalam format biner }\end{array}$ \\
\hline 6 & Perimeter & $\begin{array}{l}\text { Perintah untuk menampilkan citra } \\
\text { benih jagung dalam bentuk citra } \\
\text { perimeter }\end{array}$ \\
\hline 7 & $\begin{array}{l}\text { Nama } \\
\text { Perintah }\end{array}$ & $\begin{array}{l}\text { Menampilkan lokasi direktori citra } \\
\text { benih jagung yang ditampilkan pada } \\
\text { program dan menampilkan proses } \\
\text { yang dilakukan oleh program }\end{array}$ \\
\hline 8 & Area & $\begin{array}{l}\text { Menampilkan hasil analisis nilai area } \\
\text { objek }\end{array}$ \\
\hline 9 & Tinggi & $\begin{array}{l}\text { Menampilkan hasil analisis nilai } \\
\text { tinggi objek }\end{array}$ \\
\hline 10 & Lebar & $\begin{array}{l}\text { Menampilkan hasil analisis nilai lebar } \\
\text { objek }\end{array}$ \\
\hline
\end{tabular}




\begin{tabular}{|c|c|c|}
\hline 11 & Perimeter & $\begin{array}{l}\text { Menampilkan hasil analisis nilai } \\
\text { perimeter objek }\end{array}$ \\
\hline 12 & $\mathrm{R}$ & $\begin{array}{l}\text { Menampilkan hasil analisis nilai } r \\
\text { objek }\end{array}$ \\
\hline 13 & $\mathrm{G}$ & $\begin{array}{l}\text { Menampilkan hasil analisis nilai } \mathrm{g} \\
\text { objek }\end{array}$ \\
\hline 14 & B & $\begin{array}{l}\text { Menampilkan hasil analisis nilai } b \\
\text { objek }\end{array}$ \\
\hline
\end{tabular}

B. Nilai Batas Segmentasi Area Benih dengan Background

Operasi thresholding merupakan proses memisahkan citra area objek dengan background. Hasil analisis perbedaan nilai r, g dan b ditampilkan dalam Gambar 2 sebagai berikut.

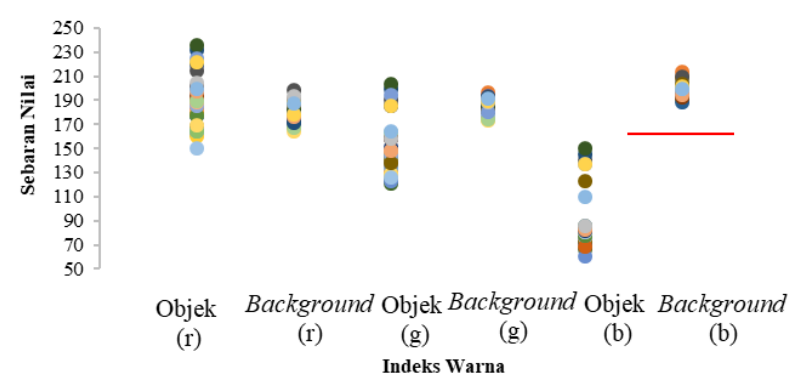

Gambar 2. Sebaran Nilai RGB Area Objek dan Background

Bedasarkan Gambar 2 nilai batas segmentasi yang digunakan untuk memisahkan background dengan objek yaitu warna b (blue). Dalam grafik diketahui nilai batas warna b (blue) sebesar 150. Dengan demikian, fungsi thresholding dapat diformulasikan dengan pernyataan jika area memiliki nilai $b<150$ maka nilai biner $=255$ atau berwarna putih sebagai objek dan jika nilai $b>150$ maka nilai biner $=0$ atau berwarna hitam sebagai background. Hasil dari proses thresholding menggunakan formula ini ditampilkan pada Gambar 3 sebagai berikut.

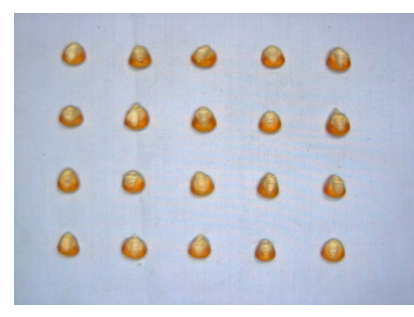

(a) Citra Asli

Gambar 3. Hasil Thresholdin

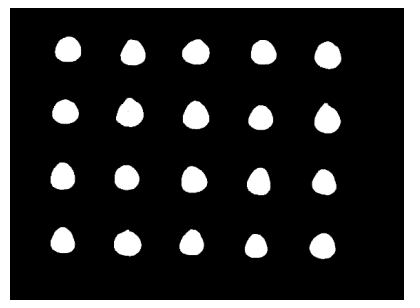

(b) Citra Biner

\section{Ekstraksi Citra}

Proses ekstraksi citra dilakukan untuk mendapatkan nilai variabel citra yang akan digunakan untuk input jaringan syaraf tiruan. Nilai dari variabel citra didapatkan dengan melakukan operasi tertentu pada piksel-piksel pembentuk citra. Variabel citra yang digunakan diantaranya yaitu area, tinggi, lebar, perimeter, indeks warna $\mathrm{r}, \mathrm{g}$ dan b. Hasil dari ekstraksi variabel citra akan disimpan dalam file text.

1. Area

Luas area sampel benih jagung didapat dari perhitungan jumlah seluruh piksel citra berwarna putih pada citra biner. Pengambilan nilai area dilakukan dengan memberi ordinat pembatas untuk setiap satu citra biner benih jagung. Pemberian ordinat pembatas dilakukan agar program pengolah citra dapat menghitung masing-masing area benih.

2. Tinggi

Tinggi sampel benih jagung didapat dari perhitungan panjang piksel berwarna putih secara vertikal pada citra biner. Perhitungan dilakukan dengan mencari ordinat paling awal dan ordinat paling akhir dari masing-masing benih jagung yang selanjutnya dihitung dengan rumus (y max-y min).

3. Lebar

Lebar benih jagung didapat dari perhitungan lebar piksel berwarna putih secara horizontal pada citra biner. Perhitungan dilakukan dengan mencari absis paling awal dan absis paling akhir dari masing-masing citra benih jagung yang selanjutnya dihitung dengan rumus (x max$\mathrm{x}$ min).

4. Perimeter

Nilai perimeter benih jagung dihitung dari penjumlahan nilai piksel perbatasan antara objek dengan background pada citra biner. Pengambilan nilai perimeter dilakukan dengan memberi ordinat pembatas untuk setiap satu citra biner benih jagung. Pemberian ordinat pembatas dilakukan agar program pengolah citra dapat menghitung masing-masing perimeter benih.

5. Indeks Warna RGB

Nilai indeks warna merah (r), hijau (g) dan biru (b) didapat dari perhitungan rata-rata nilai indeks warna merah, indeks warna hijau dan indeks warna biru pada benih jagung.

\section{Analisis Statistik Variabel Citra}

Hasil proses ekstraksi variabel citra diolah dengan program MS Excel 2016 untuk mendapatkan ukuran statistik masing-masing variabel yang berupa rata-rata, standar devisiasi, Q1, Q2, Q3, nilai minimum, dan nilai maximum. Hasil dari ukuran statistik ditampilkan dalam grafik boxplot.

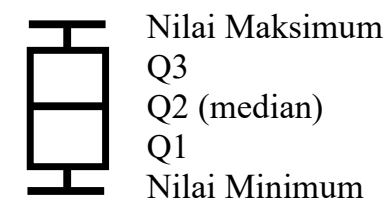

Gambar 4. Diagram Boxplot

Melalui diagram boxplot akan diketahui variabel citra yang memiliki pengaruh terhadap perbedaan varietas benih jagung. Variabel citra yang memiliki pengaruh terhadap perbedaan varietas benih jagung akan dijadikan input pada pelatihan jaringan syaraf tiruan. Penjabaran ukuran statistik masing-masing varietas hasil ekstraksi variabel citra dengan data sejumlah 3200 sampel benih jagung ditampilkan sebagai berikut.

1. Area 


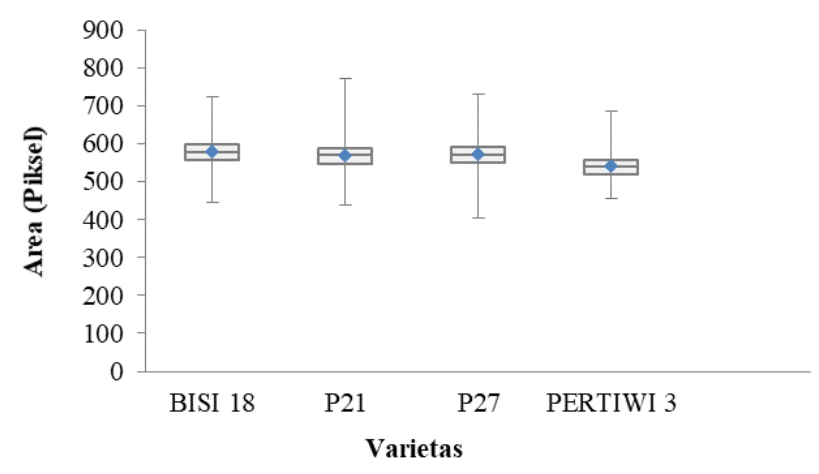

Gambar 5. Grafik Boxplot Area

Bedasarkan Gambar 5 diagram boxplot menunjukkan bahwa sebaran data nilai area setiap varietas tidak beraturan dan saling tumpang tindih. Meskipun nilai sebaran area setiap varietas saling tumpang tindih variabel citra area masih bisa digunakan sebagai input jaringan syaraf tiruan untuk membedakan varietas benih jagung.

2. Tinggi

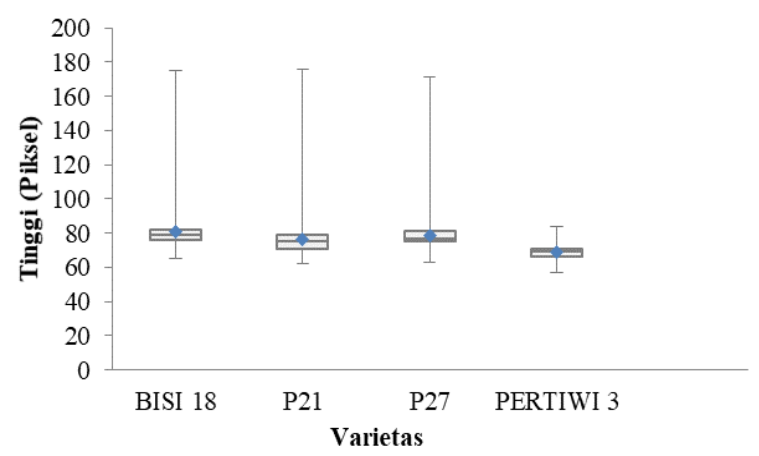

Gambar 6. Grafik Boxplot Tinggi

Bedasarkan Gambar 6 diagram boxplot menunjukkan bahwa sebaran data nilai tinggi setiap varietas tidak beraturan dan saling tumpang tindih. Adanya nilai tinggi citra setiap varietas tidak beraturan dan saling tumpang tindih disebabkan oleh pengambilan sampel benih jagung yang dilakukan secara acak. Ada beberapa sampel memiliki tinggi citra yang jauh dari rata-rata karena dalam satu tongkol jagung ukuran benih bisa berbeda. Biji dari sebuah tongkol jagung memiliki ukuran, bobot dan bentuk yang bervariasi. Umumnya, di pangkal tongkol berukuran besar, pada bagian tengah tongkol ukuran biji hampir seragam, dan berukuran kecil pada ujung [7]. Meskipun nilai sebaran tinggi setiap varietas saling tumpang tindih variabel citra tinggi masih bisa digunakan sebagai input jaringan syaraf tiruan untuk membedakan varietas benih jagung.

3. Lebar

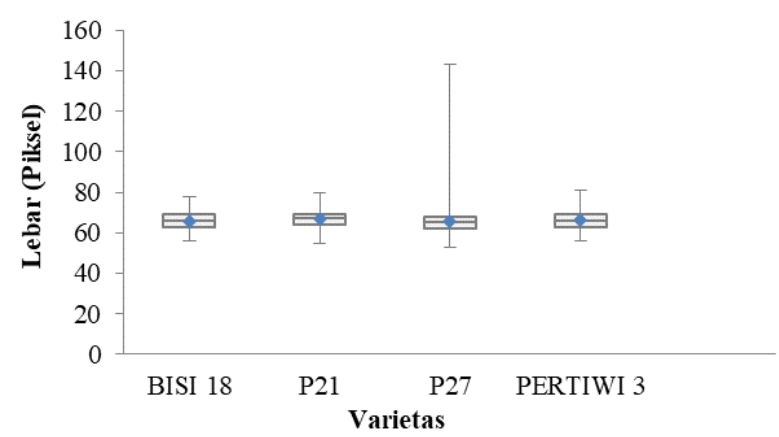

Gambar 7. Grafik Boxplot Lebar

Bedasarkan Gambar 7 diagram boxplot menunjukkan bahwa sebaran data nilai lebar setiap varietas tidak beraturan dan saling tumpang tindih. Sama halnya dengan penjelasan pada variabel tinggi bahwa pengambilan sampel benih jagung yang dilakukan secara acak menyebabkan nilai lebar citra setiap varietas tidak beraturan dan saling tumpang tindih. Namun, variabel citra lebar masih bisa digunakan sebagai input jaringan syaraf tiruan untuk membedakan varietas benih jagung.

4. Perimeter

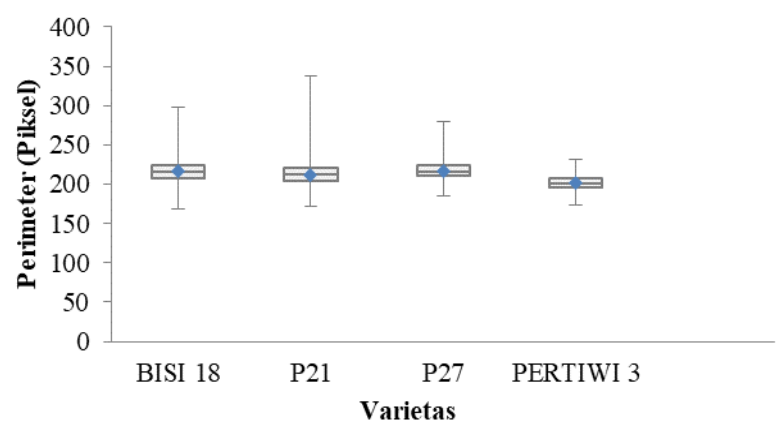

Gambar 8. Grafik Boxplot Perimeter

Bedasarkan Gambar 8 diagram boxplot menunjukkan bahwa sebaran data nilai perimeter setiap varietas tidak beraturan dan saling tumpang tindih. Meskipun nilai sebaran perimeter setiap varietas saling tumpang tindih variabel citra perimeter masih bisa digunakan sebagai input jaringan syaraf tiruan untuk membedakan varietas benih jagung.

5. Indeks Warna $r$

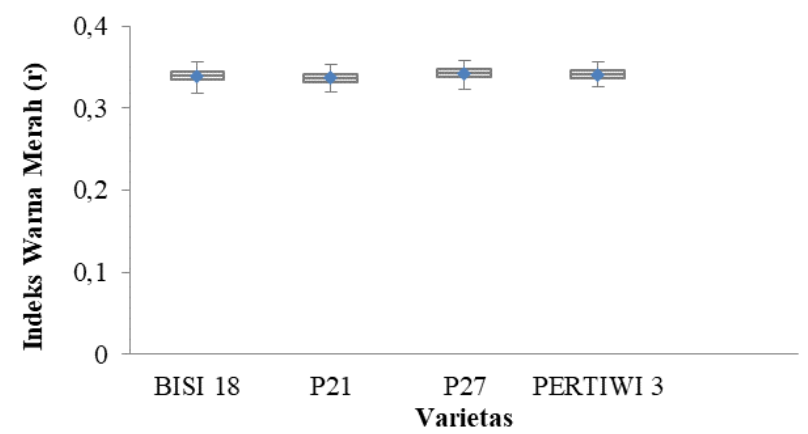

Gambar 9. Grafik Boxplot Indeks Warna r 
Grafik boxplot Gambar 9 menunjukkan nilai indeks warna merah benih jagung BISI 18, P21, P27 dan PERTIWI 3 hampir sama. Hal ini dikarenakan pada semua varietas benih jagung memiliki warnah benih yang hampir mirip. Variabel citra indeks warna merah masih bisa digunakan sebagai input jaringan syaraf tiruan untuk membedakan varietas benih jagung.

6. Indeks Warna g

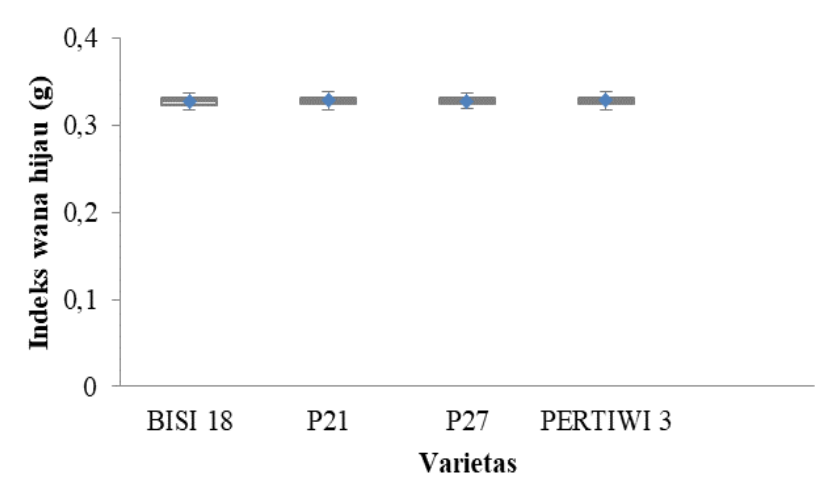

Gambar 10. Grafik Boxplot Indeks Warna g

Grafik boxplot Gambar 10 menunjukkan nilai indeks warna hijau benih jagung BISI 18, P21, P27 dan PERTIWI 3 hampir sama. Hal ini bisa dilihat dari nilai rata-rata, Q1, Q2, Q3, minimum dan maksimum setiap varietas hampir sama. Seperti halnya pada variabel citra indeks warna merah perbedaan indeks warna yang tipis pada masing-masing varietas disebabkan oleh tipe warna benih yang hampir sama. Variabel citra indeks warna hijau masih bisa digunakan sebagai input jaringan syaraf tiruan untuk membedakan varietas benih jagung.

7. Indeks Warna b

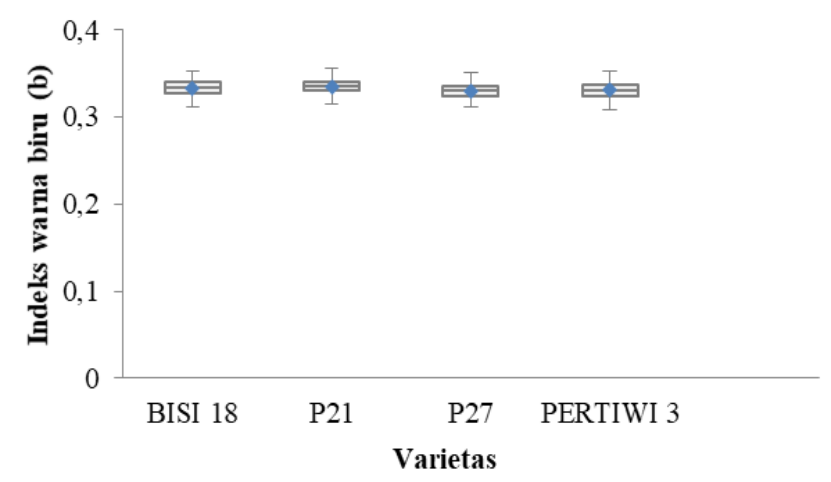

Gambar 11. Grafik Boxplot Indeks Warna b

Grafik boxplot Gambar 11 menunjukkan masing-masing diagram boxplot dari varietas benih jagung hampir sejajar. Artinya, nilai indeks warna biru benih jagung BISI 18, P21, P27 dan PERTIWI 3 hampir sama. Seperti halnya pada variabel citra indeks warna merah dan hijau perbedaan indeks warna yang tipis pada masing-masing varietas disebabkan oleh tipe warna benih yang hampir sama. Variabel citra indeks warna biru masih bisa digunakan sebagai input jaringan syaraf tiruan untuk membedakan varietas benih jagung.

E. Penentuan Variasi Jaringan Syaraf Tiruan Terbaik

Hasil analisis statistik variabel citra benih jagung menunjukkan semua variabel citra dapat digunakan sebagai input JST, meskipun ada beberapa variabel yang tumpang tindih, variabel yang tumpang tindih tersebut kemungkinan masih dapat digunakan sebagai input JST. Nilai variabel citra dinormalisasikan menggunakan metode min-max kisaran $[0,1 ; 0,9]$. Variasi dari struktur jaringan syaraf tiruan yang digunakan yaitu berdasarkan jumlah node pada lapisan tersembunyi yang terdiri dari 10 node, 15 node, 20 node, 25 node dan 30 node. Fungsi aktifasi yang digunakan pada input-hidden dan hidden-output yaitu sigmoid bipolar dengan 2 definisi target (1 dan -1). Pelatihan jaringan syaraf tiruan dilakukan pada ketiga variasi tersebut menggunakan learning rate 0,2 dan momentum 0,9 . Penghentian iterasi ditentukan bedasarkan trial and error dengan jumlah iterasi 100.000. Hasil pelatihan jaringan syaraf tiruan pada masingmasing variasi ditunjukkan pada Tabel 3 sebagai berikut.

Tabel 3. Hasil Training JST

\begin{tabular}{lcc}
\hline \multicolumn{1}{c}{ Variasi } & Identitas & $\begin{array}{c}\text { MSE (Mean } \\
\text { Squared Error) }\end{array}$ \\
\hline $\begin{array}{l}10 \text { node lapisan } \\
\text { tersembunyi }\end{array}$ & A1 & 0,58518 \\
$\begin{array}{l}15 \text { node lapisan } \\
\text { tersembunyi }\end{array}$ & A2 & 0,56411 \\
$\begin{array}{l}20 \text { node lapisan } \\
\text { tersembunyi }\end{array}$ & A3 & 0,55524 \\
$\begin{array}{l}25 \text { node lapisan } \\
\text { tersembunyi }\end{array}$ & A4 & 1,3264 \\
$\begin{array}{l}30 \text { node lapisan } \\
\text { tersembunyi }\end{array}$ & A5 & 0,55894 \\
\hline
\end{tabular}

Variasi jaringan syaraf tiruan terbaik adalah variasi yang menunjukkan kesesuaian target paling tinggi. Hasil propagasi maju data testing pada masing-masing variasi ditunjukkan pada Tabel 4 sebagai berikut.

Tabel 4. Hasil Propagasi Maju Data Testing

\begin{tabular}{lcrrrrr}
\hline & \multicolumn{4}{c}{ Kesesuaian Target } & & Akurasi \\
\cline { 2 - 5 } Variasi & BISI & P21 & P27 & $\begin{array}{c}\text { PERTIWI } \\
\text { Jumlah }\end{array}$ & $\begin{array}{c}\text { Total } \\
\mathbf{( \% )}\end{array}$ \\
\hline A1 & 105 & 83 & 93 & 165 & 446 & 55,75 \\
A2 & 118 & 76 & 99 & 157 & 450 & 56,25 \\
A3 & 110 & 92 & 104 & 160 & 466 & 58,25 \\
A4 & 102 & 78 & 102 & 154 & 436 & 54,50 \\
A5 & 118 & 81 & 100 & 153 & 452 & 56,50 \\
\hline
\end{tabular}

Bedasarkan Tabel 4 presentase kesesuaian target yang paling tinggi adalah variasi A3 dengan menggunakan lapisan tersembunyi 20 node. Variasi A3 memiliki persentase kesesuaian sebesar 58,25\% dengan jumlah target yang sesuai sebesar 466 dari 800 sampel data testing. Beberapa citra benih pada masing-masing varietas dianggap sebagai citra 
benih lain. Hal ini tampak pada diagram boxplot yang saling tumpang tindih pada masing-masing variabel citra.

F. Integrasi Program Pengolahan Citra dengan Jaringan Syaraf Tiruan

Proses integrasi program pengolahan citra dengan jaringan syaraf tiruan dilakukan dengan cara memasukkan bobot-bobot hasil pelatihan jaringan syaraf tiruan yang terbaik dari Matlab kedalam program identifikasi varietas benih jagung. Bobot tersebut digunakan sebagai input program dalam fungsi propagasi maju, sehingga program akan otomatis melakukan pendugaan varietas benih jagung ketika membaca citra benih jagung. Berikut ini merupakan tahapan proses integrasi program pengolahan citran dengan jaringan syaraf tiruan.

1. Normalisasi data input

Data yang digunakan sebagai input jaringan syaraf tiruan yaitu tujuh variabel citra hasil ektraksi program pengolahan citra. Variabel citra yang menjadi input yaitu area, panjang, lebar, perimeter, indeks warna $r$, g dan $b$. Seluruh data input dinormalkan terlebih dahulu dengan menggunakan metode min-max kisaran data 0,1 sampai 0,9. Normalisasi data ini dilakukan agar nilai dapat dioperasikan dalam fungsi aktivasi sigmoid bipolar dalam proses propagasi maju.

2. Propagasi maju

Data input yang telah dilakukan normalisasi diolah dengan menggunakan fungsi propagasi maju dengan bobot-bobot hasil pelatihan jaringan syaraf tiruan terbaik. Fungsi aktivasi yang digunakan dalam proses prpagasi maju yaitu fungsi sigmoid bipolar. Hasil dari proses propagasi maju yaitu nilai output yang berupa bilangan bipolar (1 dan -1).

3. Pendugaan varietas

Nilai bilangan bipolar yang dihasilkan dari proses propagasi maju diterjemahkan sebagai varietas benih jagung. Definisi target varietas benih jagung ditunjukkan pada Tabel 5 sebagai berikut.

Tabel 5. Definisi Target Varietas

\begin{tabular}{lcc}
\multicolumn{1}{c}{ Output } & Y1 & Y2 \\
\hline BISI 18 & 1 & 1 \\
P21 & -1 & 1 \\
P27 & 1 & -1 \\
PERTIWI 3 & -1 & -1 \\
\hline
\end{tabular}

Informasi varietas menjadi tambahan pada output file text. Output ini selanjutnya digunakan untuk melakukan validasi program. Tampilan akhir dari program identifikasi benih jagung yang telah diintegrasikan dengan jaringan syaraf tiruan ditampilkan pada Gambar 12 sebagai berikut.

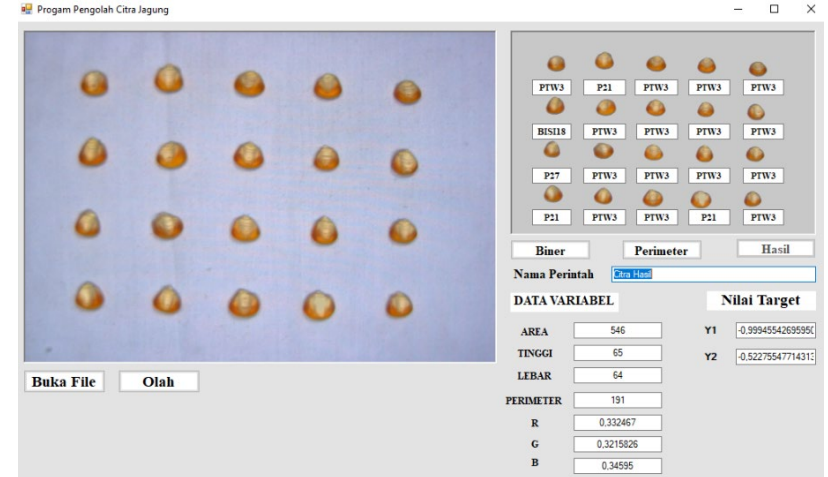

Gambar 12. Tampilan Program Identifikasi Varietas Benih Jagung

G. Validasi Program Identifikasi Benih Jagung

Proses validasi dilakukan untuk mengetahui tingkat akurasi program dalam pendugaan varietas benih jagung. Proses validasi dilakukan dengan program identifikasi varietas benih jagung untuk menduga varietas benih pada 800 data testing. Validasi hasil program identifikasi varietas benih jagung dianalisis menggunakan tabel confusion matrix untuk mempermudah analisis tingkat akurasi program. Confusion matrix hasil validasi program identifikasi varietas benih jagung ditampilkan pada Tabel 6 sebagai berikut.

Tabel 6. Confusion Matrix Hasil Validasi Program

\begin{tabular}{|c|c|c|c|c|c|c|c|}
\hline \multirow{2}{*}{$\begin{array}{c}\text { Jenis } \\
\text { Varietas }\end{array}$} & \multicolumn{4}{|c|}{ Prediksi } & \multirow{2}{*}{$\begin{array}{l}\text { Total } \\
\text { Baris }\end{array}$} & \multirow{2}{*}{$\begin{array}{c}\text { Aku } \\
\text { rasi } \\
\text { Pro } \\
\text { duksi }\end{array}$} & \multirow{2}{*}{$\begin{array}{c}\text { Kesalah } \\
\text { an } \\
\text { Omisi }\end{array}$} \\
\hline & $\begin{array}{c}\text { BISI } \\
18 \\
\end{array}$ & $\begin{array}{c}\text { Pioneer } \\
\text { P21 }\end{array}$ & $\begin{array}{c}\text { Pioneer } \\
\text { P27 }\end{array}$ & $\begin{array}{c}\text { PERTIWI } \\
\mathbf{3} \\
\end{array}$ & & & \\
\hline BISI 18 & 125 & 21 & 43 & 11 & 200 & 62,5 & 37,5 \\
\hline Pioneer P21 & 85 & 87 & 10 & 18 & 200 & 43,5 & 56,5 \\
\hline Pioneer P27 & 70 & 15 & 104 & 11 & 200 & 52,0 & 48,0 \\
\hline PERTIWI 3 & 8 & 25 & 10 & 157 & 200 & 78,5 & 21,5 \\
\hline Total Kolom & 288 & 148 & 167 & 197 & 800 & & \\
\hline $\begin{array}{l}\text { Akurasi } \\
\text { User }\end{array}$ & 43,4 & 58,8 & 62,3 & 79,7 & & & \\
\hline $\begin{array}{l}\text { Kesalahan } \\
\text { Komisi }\end{array}$ & 56,6 & 41,2 & 37,7 & 20,3 & & & \\
\hline $\begin{array}{l}\text { Akurasi } \\
\text { Total }\end{array}$ & & & & 59,1 & & & \\
\hline
\end{tabular}

Hasil dari validasi program identifikasi varietas benih jagung menunjukkan tingkat akurasi total sebesar 59,1\%. Hal ini berarti identifikasi varietas benih jagung oleh program belum maksimal. Meskipun hasil validasi program identifikasi benih jagung berbasis jaringan syaraf tiruan belum maksimal, program yang dibangun dengan algoritma backpropagation dengan variabel identifikasi varietas ini sudah mampu membedakan setiap varietas dan mampu mengidentifikasi benih jagung dengan tepat sejumlah 473 benih dari total 800 benih.

\section{KESIMPULAN}

Proses identifikasi varietas benih jagung dapat dilakukan dengan menggunakan pengolahan citra digital dengan variabel citra area, tinggi, lebar, perimeter, indeks warna $R$, 
G dan B yang digunakan sebagai input jaringan syaraf tiruan. Arsitektur jaringan syaraf tiruan terbaik untuk identifikasi varietas benih jagung yaitu variasi A3 dengan menggunakan 7 input data, normalisasi data min max (kisaran data 0,1 sampai 0,9), lapisan tersembunyi sebanyak 20 node, 2 definisi target (1 dan -1), bobot awal Nguyen Widrow, fungsi aktivasi pada input-hidden dan hidden-input menggunakan sigmoid bipolar, jumlah iterasi sebesar 100.000, learning rate 0,2 dan momentum 0,9. Hasil dari proses validasi jaringan syaraf tiruan menunjukkan bahwa tingkat akurasi program dalam mengidentifikasi varietas benih jagung yaitu sebesar $59,1 \%$.

\section{REFERENSI}

[1] Ahmad, U. (2005). Pengolahan Citra Digital dan Teknik Pemrogamannya. Jakarta : Graha Ilmu.

[2] Soedibyo, D.W. (2006). Pemutuan Edamame (Glycine Max (L) Merrill.) dengan Menggunakan Pengolahan
Citra (Image Processing) (Tesis). Bogor: Institut Pertanian Bogor (IPB).

[3] Wiharja, Y.P. \& Harjoko, A. (2014). Pemrosesan Citra Digital untuk Klasifikasi Mutu Buah Pisang Menggunakan Jaringan Saraf Tiruan. IJEIIS, Vol. 4, No. 1, pp. 57-58

[4] Sugianto, A.A. (2015). Pemutuan Buah Cabai Merah Besar (Capsicum annum L.) Menggunakan Pengolahan Citra Digital dan Jaringan Syaraf Tiruan (Skripsi). Jember: Jurusan Teknik Pertanian Fakultas Teknologi Pertanian Universitas Jember.

[5] Siang, J.J. (2005). Jaringan Syaraf Tiruan dan Pemrogamannya Menggunakan Matlab. Yogyakarta: Andi.

[6] Kusumadewi, S. (2004). Membangun Jaringan Syaraf Tiruan Menggunakan MATHLAB \& EXCEL LINK. Yogyakarta: Graha Ilmu.

[7] Azrai, M. (2003). Prospek Penggunaan Marka Molekuler Untuk Pemuliaan Tanaman Jagung. Balai Penelitian Tanaman Serealia Maros. 